\title{
Resistance To Liberalization: The Effects Of Individual Decision Making On Opposition To Multilateral Liberalization Through The WTO
}

\author{
Lynda D. Vargha (E-mail: lvargha@skidmore.edu), Skidmore College
}

\begin{abstract}
This paper examines the sources of the resistance to liberalization in the United States and its effects on the political climate in which the WTO member nations continue to pursue liberalization. This analysis utilizes the findings of mainstream economic theory to argue that opposition to the WTO is rooted in rational economic decision-making. A majority-voting model is used to more formally illustrate that this rational decision making affects the composition of public opposition and results in a resistance to liberalization by a majority of the populace, even if a majority will benefit from the movement toward free trade. The paper concludes with a discussion of the policy implications of the theoretical analysis focusing on the importance of Trade Adjustment Assistance and continued multilateral liberalization through the WTO.
\end{abstract}

\section{Introduction}

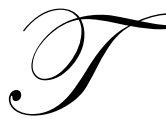

he November 1999 Inter-Ministerial Meeting of the World Trade Organization in Seattle was meant to serve as the beginning of the Millennium round of trade negotiations for the members of the World Trade Organization (WTO). Even before protesters scaled buildings and smashed windows in Seattle, the WTO was under scrutiny in the U.S. and abroad from both the left and the right. Groups such as trade unions, NGOs, and grassroots organizations spoke out against the WTO on issues ranging from globalization to labor conditions and environmental policies, while right wing organizations called for less open boarders for goods, services, and immigration. However, at the time, many mainstream economists did not take this opposition seriously, dismissing it as left-wing or right-wing politics or a lack of understanding of the theory of comparative advantage and gains from trade.

Upon further inspection, this reaction by economists seems unwarranted. While those protesting the WTO meeting in Seattle represented a minority of the U.S. public, there exists evidence that most Americans shared some of their concerns. A 2001 study by the Institute for International Economics found that a majority of Americans surveyed do understand the benefits of international trade but are concerned about its costs, particularly the loss of jobs and effects on wages (Scheve and Slaughter, 2001). Specifically, "Americans display a quantitatively accurate appreciation of both the benefits and the costs of liberalization but that a consistent plurality or majority tend to weigh the costs more heavily than the benefits" (Scheve and Slaughter, p. 13). In addition, the authors found that most Americans surveyed believe that the current pace of liberalization is too fast. As a result, "for every American who self-identifies with free trade, nearly nine others support interventionist trade policies." (Scheve and Slaughter, p.28)

In this paper, I examine the sources of the resistance to liberalization in the United States and its effects on the political climate in which the WTO member nations continue to pursue liberalization. The next section utilizes the findings of mainstream economic theory to argue that opposition to the WTO is rooted in rational economic decision making. The following section uses a majority voting model to illustrate, more formally, that this rational 
decision making affects the composition of public support for liberalization and results in a resistance to liberalization by a majority of the populace, even if a majority will benefit from it. The paper concludes with a discussion of the policy implications of the theoretical analysis focusing on the importance of Trade Adjustment Assistance and continued multilateral liberalization through the WTO.

\section{Rational Decision Making}

Mainstream economic theory predicts that the reduction of import tariffs and nontariff barriers will result in an increase in imports, a decrease in profits for import competing industries and a reduction in wages and a loss of jobs for workers in those industries. As a result, it is rational for owners of capital and sector-specific jobs skills in domestic import competing industries to oppose policies aimed at lowering import tariffs. Yet, with a majority of Americans opposing further liberalization, it is apparent that opposition extends beyond these producers and consumers. This is sometimes puzzling to mainstream economists, however, this paper will illustrate that such behavior is rooted in economically rational decision-making and should not be dismissed as ignorance or political reactionism.

Despite their understanding of the costs and benefits of liberalization, it is true that Americans lack information about specific trade policies. A 1994 NBC/Wall Street Journal poll found that "nearly 40 percent of Americans said that they did not know enough to evaluate whether the Uruguay Round of the GATT would benefit the United States" (Scheve and Slaughter, p. 42). Since individuals lack this specific information, they fall back on their general understanding of the costs and benefits of liberalization when evaluating their position on a specific policy.

However, this lack of information does not necessarily result in the resistance to liberalization. Survey evidence illustrates that Americans do understand that the overall gains from liberalization are greater than the losses. Instead, opposition stems from the fact that Americans tend to weight the losses more heavily than the gains (Scheve and Slaughter 2001). This asymmetry in weighing gain and loss is consistent with psychological evidence about individual decision-making. Psychologists Kahneman and Tversky (1984) found that individual decision making is characterized by loss aversion which means that the utility received from gaining an object is less than the disutility of losing it. Therefore, an individual frames a decision in terms of gains and losses and weighs the loss greater than they would a gain of an equal magnitude. This concept is exhibited in daily economic decisions and is a rational part of economic decision making.

This avoidance of loss extends beyond individual decision-making and is also rational for a government determining trade policy. This concept is most prominently presented by Corden (1974), who asserted that it is rational for government policy decisions to be based on what he named the "conservative welfare function." At the core of the conservative social welfare function is the principle that a government should avoid a considerable reduction in the income of a particular group both out of government self interest and equity concerns. Specifically, it states that: "1) It is considered unfair for any policy to substantially and arbitrarily injure one party for the benefit of others. 2) The existence of such a principle provides a degree of "social insurance" to all members of the public against unexpected losses of income. 3) The policy buys social peace by avoiding discontent" (Corden, p. 174). Based on Corden's work, even if a government does not display social concern for those harmed by liberalization, it is still best off to avoid this loss in order to provide social insurance and "avoid discontent" among its electorate.

Fortunately, there is a policy solution that will help to avoid discontent, provide social insurance, and lessen public resistance to liberalization. While Americans understand that lowering tariffs will result in less expensive goods, they are bothered by the costs of job loss and lower wages. Therefore, "opinions become more favorable toward liberalization when it is explicitly linked to adjustment assistance for workers" (Scheve and Slaughter, p. 9). This implies an important role for Trade Adjustment Assistance for workers as a part of future liberalization. In addition, American opinion about liberalization is more favorable if our trading partners are also expected to liberalize suggesting a continued U.S. commitment to cooperative multilateral liberalization through the WTO. These policy implications will be discussed in the results section of this paper. 


\section{Theoretical Analysis}

Given the rational basis for resistance to liberalization, this section presents a more formal analysis, using a median voter model to illustrate how the asymmetric weighing of loss and gain will translate into to resistance to liberalization.

Mayer (1984) posits a median voter model that identifies the specific winners and losers from liberalization. The model is a Heckscher-Ohlin small country model where two commodities (X1 and X2) are produced using two factors of production ( $\mathrm{L}$ and $\mathrm{K}$ ). Markets are competitive, production functions are homogenous to degree one, and labor and capital are mobile between industries. An individual's labor and capital ownership are represented by $\mathrm{Li}$ and $\mathrm{Ki}$ respectively where $\mathrm{i}=1, \ldots, \mathrm{I}$, assuming that $\mathrm{Li}=1$ and $\mathrm{Ki}>0$ for all $\mathrm{i}$.

Mayer (1984) illustrates that given a symmetric factor ownership distribution, symmetric voting costs and symmetric voting probabilities, the unique equilibrium tariff level (one that cannot be voted out through majority voting) will be free trade. In order for the equilibrium tariff to be something other than zero, one must assume there exists an asymmetry in factor ownership, voting costs, or voting probabilities.

Mayer defines $\mathrm{Di}(\mathrm{ki}, \mathrm{t})$ as the change in agent i's real income resulting from a tariff decrease. From his analysis of the model he finds the following expression for Di:

$$
D_{i}=\frac{\left(w^{\wedge}-\mathrm{r}^{\wedge}\right)}{\mathrm{p}^{\wedge}(1+\mathrm{t})} \times\left[\frac{\mathrm{Ywr}\left(\mathrm{ki}_{\mathrm{i}}-\mathrm{k}_{\mathrm{j}}\right)}{\left(\mathrm{w}+\mathrm{rkj}_{\mathrm{j}}\right)(\mathrm{wL}+\mathrm{rK})}\right] .
$$

where $\mathrm{w}^{\wedge}$ is the percentage change in the wage, $\mathrm{r}^{\wedge}$ is the percentage change in the return to capital, and $\mathrm{p}^{\wedge}$ is the percentage change in price. The variable kj represents the capital ownership of the individual for whom the current tariff rate is optimal. The above equation provides the result that if agent $i$ is relatively well (poorly) endowed with the factor that is used intensively in the production of the import good, he/she will lose (gain) from a tariff decrease. For example, a relatively capital abundant country will import labor intensive goods. A tariff reduction on these goods will benefit individuals with a high level of capital ownership and harm individuals with a relatively low level of capital ownership.

This portion of the model can be used to explain the source and policy implications of the current resistance to liberalization in the United States. As a relatively capital abundant country, the U.S. has a tariff structure that is characterized by historically high tariffs on labor intensive imports. The majority of the populace would benefit from unilateral lowering of these tariffs as consumers would face lower world prices on these goods, and the gains to consumers would outweigh the losses incurred by import competing domestic producers. In Figure 1, D locus identifies the winners and losers from a tariff decrease given that $\mathrm{t} j$ is the prevailing tariff level. Assume that there is some positive tariff level (tj), which is optimal for an agent with capital endowment $\mathrm{k}(\mathrm{ej})$. Those with a factor ownership ratio less than $\mathrm{k}(\mathrm{ej})$ will gain from the tariff decrease, and those with a tariff level greater than $\mathrm{k}(\mathrm{ej})$ will lose. Therefore, a majority of the populace will benefit from a unilateral tariff decrease.

The D locus represents the actual costs and benefits of a tariff reduction, however, the perceived benefits are less than the actual benefits due to the asymmetric weighing of loss and gain. Once this aspect of individual decision-making is factored in, the reason for the resistance to liberalization becomes clear. Assume that the is some additional cost of liberalization $(\alpha>0)$ that is perceived by the individual as a result of the additional weight placed on the income and wage losses caused by the tariff decrease. The locus of perceived gains and losses from a tariff decrease is represented by D- $\alpha$ in Figure 1.

Note that the perceived benefits line is not parallel to the actual benefits line due to assumptions about the difference in the magnitude of $\alpha$ for individuals with different levels of capital ownership. Concerns about the costs of liberalization center around wage and job loss, and these concerns are greater among individuals with low capital ownership. Specifically, Scheve and Slaughter (2001) find that the opposition to liberalization tends to be negatively 
correlated with worker education level and wage. Assuming that low skill workers have a less than average capital ownership, $\alpha \square$ is likely to be larger for those with lower capital ownership.

\section{Results And Policy Implications}

There are two major results of the above analysis. First, the gains from liberalization are smaller when the individual decision making process is taken into consideration. In particular, there is a perception that those losing from liberalization (low capital ownership end of the D locus) are hit particularly hard. As a result, it is individually rational for those with the most to lose from liberalization to be involved in protest aimed at the WTO. While this does not justify vandalism or violence, we should not be surprised by the existence of small, vocal and active pockets of resistance.

Second, it is rational, given the individual's decision-making process, for this resistance to extend beyond these small pockets to a majority of Americans. It is individually rational for most Americans to oppose liberalization, even if the static gains from trade outweigh the costs, because they do not perceive a net benefit from it. As shown in Figure 1, if $\alpha$ is sufficiently large, a majority of the populace will oppose liberalization, even if a majority would benefit from it.

There are two major policy implications that follow from these results. The first involves the role of domestic government and trade adjustment policy. At the lower end of the capital ownership scale are consumers who marginally gain from liberalization but are willing to pay slightly higher prices to protect against job loss and wage reduction for other workers. However, "opinions become more favorable toward liberalization when it is explicitly linked to adjustment assistance for workers" (Scheve and Slaughter, p. 9). Therefore, a government providing trade adjustment assistance will not only help integrate displaced workers back into the labor force, it will reduce the resistance to liberalization by its populace.

The results of such a policy can be seen in Figure 2. Trade Adjustment Assistance defrays some of the costs of unemployment caused by liberalization, and it reduces public resistance to the liberalization process. Assume that this per person benefit can be measured by the variable $\beta$ and that the value of $\beta \square$ is greater for those with low capital ownership. Therefore, Trade Adjustment Assistance will shift the $\mathrm{D}-\alpha$ curve up by $\beta$, increasing the number of individuals who support liberalization.

A second policy implication involves the importance cooperative multilateral liberalization and the future of the WTO. If a country engages in multilateral liberalization with its major trading partners, it will enjoy gains that result from the opening of foreign markets to domestic exports. As a result, multilateral liberalization will result in increased benefits to domestic owners of $\mathrm{K}$, who now have a larger market for their goods, and is likely to increase their support for liberalization. In addition, survey data provides evidence that more Americans support U.S. liberalization when trading partners are also required to liberalize (Scheve and Slaughter, 2001). Thus, multilateral liberalization provides both real economic benefits as well as perceived benefits when compared to unilateral liberalization.

Figure 3 illustrates this comparison of the effects of unilateral and multilateral liberalization. Assume that the additional benefits from multilateral liberalization can be represented by an individual net gain of $\chi$. Therefore, the net gain from a multilateral tariff decrease will be represented by the locus D $-\alpha+\chi$. As compared to unilateral liberalization (the $\mathrm{D}-\alpha$ line), more individuals will receive or perceive a net gain from liberalization. As a result, a smaller percentage of the populace will oppose multilateral liberalization than unilateral liberalization and implying an important role for cooperative liberalization in removing protection in labor intensive import competing industries.

\section{Conclusion}

While the analysis provided in this paper does not explain all resistance to the WTO, it uncovers some important themes and policy implications. First, it is rational for a minority of citizens to protest further liberalization through the WTO. While this does not justify vandalism or violence, we should not be surprised by the existence of 
small, vocal and active pockets of resistance. Second, it is rational, given the individual's decision-making process, for this resistance to extend beyond these small pockets to a majority of Americans. Due to the way we evaluate gain and loss and lack of complete information about specific policies, individuals fall back on general knowledge about liberalization and the asymmetric weighing of loss. These results are consistent with the varying levels of resistance to trade liberalization through the WTO and will serve to impede the future progress of the WTO if left unrecognized.

Therefore, WTO member nations cannot afford to ignore the resistance expressed by their citizens. Instead, they must recognize the rationale of the opposition to WTO policies and take steps to uncover the source of resistance and come up with the appropriate policy solutions. Specifically, these findings serve as a warning regarding future WTO policy. It is important to note that opposition does not only come from those losing from liberalization but from those who understand the gains from trade but are concerned about the job loss and reduction of wages in some industries that result from tariff reduction. This implies a role for the U.S. government in providing compensation to those losing from liberalization. For example, further liberalization must be combined with an expansion of programs such as Trade Adjustment Assistance to workers subject to job loss as a result of liberalization.

Finally, these results also serve as a reminder of the importance of cooperative policy-making through the WTO. As illustrated in the previous section, if a country, such as the United States went about reducing tariffs unilaterally, it would meet more resistance to this policy than if tariff reduction were done multilaterally. Therefore, WTO agreements mandate new lower tariff levels at home and abroad and provide an enforce mechanism and dispute settlement procedure to assure adherence to these policies.

\section{References}

1. Corden, W. M. (1974), Trade Policy and Economic Welfare, Clarendon Press: Oxford.

2. Kahneman, D. and Tversky, A. (1984), "Choices, Values and Frames," American Psychologist, 39, 341-350.

3. Mayer, W. (1984), "Endogenous Tariff Formation,” American Economic Review, 74, 970-985.

4. Scheve, K. and Slaughter, M. (2001), Globalization and the Perceptions of American Workers. Institute for International Economics: Washington, D.C.

Figure 1: Gains And Losses From A Tariff Decrease

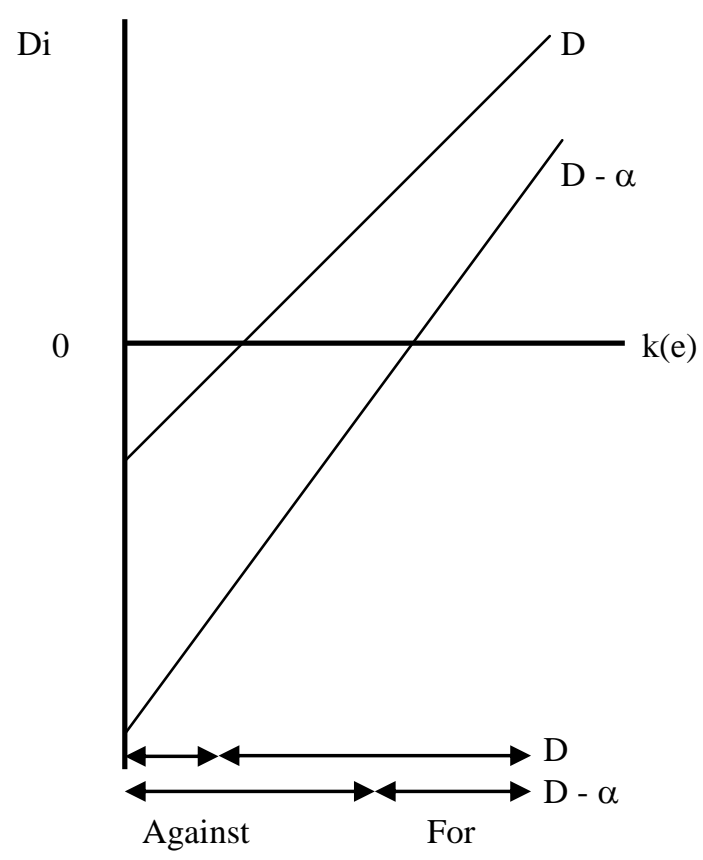


Figure 2: Tariff Decrease With Trade Adjustment Assistance

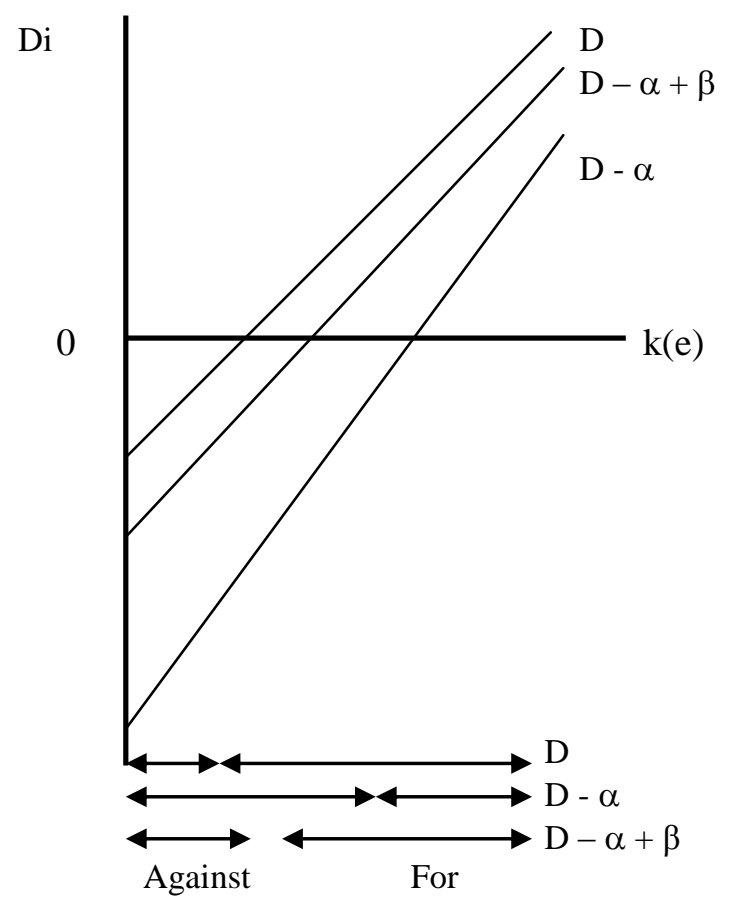

Figure 3: Tariff Decrease Under Multilateral vs. Unilateral Tariff Reduction

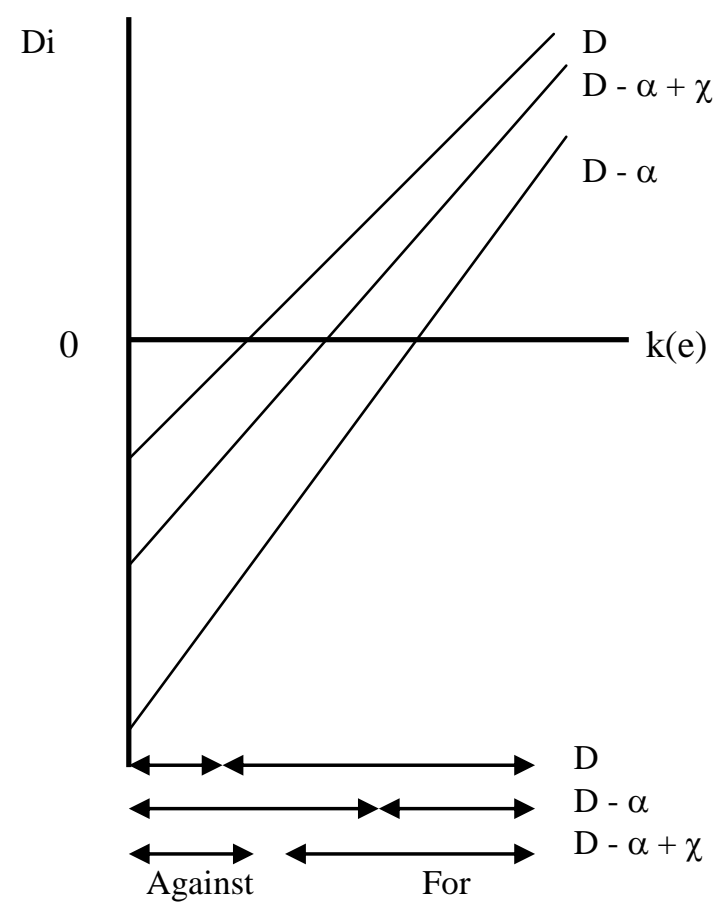

